\title{
Foreign language anxiety - an issue of (Czech) Slovak teachers - critical review
}

\author{
Gabriela Mikulová \\ Constantine the Philosopher University in Nitra, Slovakia; tanistrakova.g@gmail.com
}

\begin{abstract}
The monograph, "Foreign Language Anxiety, Post - Communist Country Context" was edited by Zdena Král'ová and Jana Kamenická, Verbum Praha, 2019.

Anxiety and fear on one hand, unflagging inner responsibility to do one's best in the position of a role model, on the other... This is the challenge that countless non-native foreign language (FL) teachers experience every time they stand in front of their learners. Teachers, being of different personalities, having undergone various educational systems and being given different opportunities for practical foreign language use, are trying to do their best to fulfil their highest potential. That is why being a teacher automatically predestines representatives of this difficult profession to experience a life-long
\end{abstract} challenge - professional and personal.

Many non-native FL teachers experience feelings of anxiety and fear when it comes to their everyday teaching performance, however, their, often very difficult, situation does not belong to topics of wide discussions. This work provides a unique outlook on the issues that should definitely be more discussed by the experts of the field. Authors try to clarify the issue of anxiety in hope that if it is theoretically understood, it can be coped with it more efficiently. During close reading of this monograph, I, as a nonnative English language teacher, have found many issues concerning anxiety not only interesting, but beneficial as well. The content of the work is logically organized which gives readers the opportunity to understand the problem systematically, from the most fundamental issues to more complex ones.

In the introductory chapter, the author provides readers with a compact historical, biological and psychological viewpoint on anxiety in general, which makes the issue more understandable and, therefore, beneficial for people engaged with the topic. Due to my own observation of in-service teachers on one hand and much research done to the topic, on the other, it is apparent that teachers are very often considered by the general public to be all-knowing title-holders who are obliged to not only educate, but raise their students as well. Therefore, many teachers are constantly under the pressure and may not realize that the feelings they experience are symptoms of an anxious teacher. The author (Morais) presents a minute description of components of anxiety (physical symptoms, thoughts, avoidance behavior, expression of aggression, etc.), which the reader can possibly identify with and realize that anxiety does not have to be just a theoretical issue of "a special category of teachers", but an urgent condition that needs to be dealt with, though.

Public awareness of Foreign Language Anxiety (FLA) gradually rises which is very important for both, teachers and learners. Král'ová in the second chapter summarizes the most relevant information concerning FLA - definitions, classification, causes, factors and subtypes, and presents the overview of research findings on FLA from the very beginning of its study in the 1970s up to the present day. She introduces FLA to a general audience because it may have a significant impact on the FL mastering. Despite the fact there is an undeniable connection between anxiety and foreign language mastering, the author argues that it cannot be definitely concluded whether self-perceived unsatisfactory level of foreign language competence leads to FLA or FLA affects the level of mastering a foreign language.

An equal significance is given to strategies designed to alleviate anxiety - to coping strategies. Král'ová introduces three strategies that can be applied when dealing with FLA: teaching, learning, and intervention strategies. These are based on individual approaches (cognitive, affective and behavioral) that can help individuals to get rid of anxiety or, at least, to make it more bearable. Theoretical information is completed with the research overview verifying individual strategies and approaches. In different conditions, different approaches can be used, however, "the combination of cognitive, 
behavioral and affective approaches in foreign language learning and teaching appeared to be the recipe for success" (Král'ová, p. 56).

When overcoming any difficulty or a problem in our life, the first step to improve the situation is to understand the problem or principles of its creation, in other words, get to the root of things. Having FLA in the center of attention, the cognitive-behavioral approach is understood to be one of the keys. As authors (Morais, Petrová) state, the approach has two basic principles:

1. our cognition has a controlled impact on our emotions and behavior,

2. our acting and behavior can strongly influence our thoughts and emotions.

Providing given approaches seems, from my personal point of view, to be extremely helpful due to the fact that any anxious teacher can try to understand what is "behind" their anxiety, what might all these feelings stem from or, at least, that their unenviable situation is solvable. Reading such a text can give anxious learners or teachers hope whose meaning is beyond description. Theoretical explanation is followed by the summary of techniques and methods used for coping with anxiety, including relaxation procedures, breathe exercises or work with thoughts. I consider given exercises to be really helpful, but many anxious teachers might not have known about them before, and due to the lack of information and discussions, they often choose an escape strategy of any kind, which consequently has an unfavorable impact not only on themselves, but on their learners as well.

The importance of the issue is undeniably huge while FLA is a problem of non-native teachers of any nationality, however, prominence of this work is given to Slovak non-native English language teachers. Authors (Králová, Malá) provide readers with a historical overview of educational systems within the Slovak republic, where long-lasting historical and political changes have directly affected English language teachers' performance and feelings of anxiety. The transformation from 40 years lasting communist regime to an independent democratic state was a difficult process bringing numerous educational changes, foreign language preferences, teacher education modifications as well as an unrestricted movement abroad. Significant findings within this context were detected by Králová and Malá (2018) who discovered that more practiced foreign language teachers often experience higher speaking anxiety due to previous socio-political factors and the lack of communication with native speakers. This issue has come into existence under the term "post-communist countries' paradox" and serves as another important feature in the effort to comprehend anxiety in the case of non-native $\mathrm{FL}$ teachers.

Finally, the work outlines an overview of opportunities for the professional development of teachers in Slovakia, by which they can maintain life-long education. Kováčiková mentions continual education, credit system, EU programs, non-governmental teacher associations, international certificates for teaching English and private sector offering workshops and methodological instructions. All of the aforementioned opportunities are accessible to teachers and can significantly enhance their $\mathrm{FL}$ proficiency and self-confidence, which will subsequently reduce their anxiety as well.

The work provides readers with numerous beneficial information (cognitive-behavioral approach, nature of anxiety), introduces findings that address topics which need to be taken into consideration and definitely researched in the near future (teachers' foreign language anxiety, post-communist countries' paradox), provides different techniques and methods that can be used even at work to release anxiety and relax, or it points to changes that needs to be performed if pre-service teacher preparation was to be beneficial for themselves and for their future learners as well. Context of the work is organized in a logical order, individual issues connect to each other and, what is of the highest importance, information published in the work make readers think about the issues, which is the first step if progress in this field is to be enhanced.

I highly agree with the opinion of authors of this monograph who state that if we want the overlooked situation of non-native foreign language teachers to be improved, it would be efficient to deal with and introduce long-lasting preparation of pre-service teachers, not only in the educational 
field, but in the mental training as well, so that teachers are prepared for their not easy, but extremely interesting profession.

The content of the work is not, however, beneficial only for pre-service and in-service non-native teachers of foreign languages. I would highly recommend it to the wide public who are connected to the teaching-learning process in any way, including learners and their parents as well. These days when the authentic form of any foreign language is easily accessible, learners are watching film and videos in the native language, they play computer games, chat with their friends all around the world or are able to travel abroad and experience the country in all its aspects, to teach the foreign language at schools has become a great challenge for language teachers.

Due all the aforementioned facts, it is important to concentrate not only on learners and their learning problems, but teachers in the first place. When enough attention is given to those who are considered to be knowledge bearers, the outcome will be mirrored in motivated, educated and balanced learners who can understand the significance of learning. What needs to be done, however, is to start from the very beginning and that is exactly what this work aims at. 